\title{
Load Dependence of Proximal Tubular Fluid and Bicarbonate Reabsorption in the Remnant Kidney of the Munich-Wistar Rat
}

\author{
David A. Maddox, James F. Horn, Frank C. Famiano, and F. John Gennari \\ Department of Medicine, University of Vermont College of Medicine, Burlington, Vermont 05405
}

\begin{abstract}
Studies were undertaken to characterize the pattern of proxi-

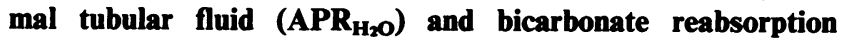
$\left(A P R_{\mathrm{HCO}_{3}}\right)$ in the remnant kidney of euvolemic Munich-Wistar rats. The remnant kidney rats were placed on a diet containing either low or normal protein. Collections were obtained in the early, mid-, and late proximal convoluted tubule. Single nephron glomerular filtration rate (SNGFR) increased from $40.2 \mathrm{nl} / \mathrm{min}$ in controls to $58.8 \mathrm{nl} / \mathrm{min}$ in low protein remnant kidney and $78.1 \mathrm{nl} / \mathrm{min}$ in normal protein remnant kidney rats. The filtered load of bicarbonate was $1,272,1,641$, and $2,013 \mathrm{pmol} / \mathrm{min}$, in the three groups, respectively. $\mathbf{A P R} \mathbf{H}_{2} \mathrm{O}$ and $\mathbf{A P R} \mathbf{H C O}_{3}$ increased nearly in parallel. Most of the increase in reabsorption occurred in the early proximal tubule. Tubular hypertrophy could account for at least $20-40 \%$ of the increase in reabsorption, but the majority of the increase appeared to be a delivery-dependent response similar to that observed in normal rats after an acute increase in SNGFR.
\end{abstract}

\section{Introduction}

When kidney tissue is removed surgically in the rat, the single nephron glomerular filtration rate (SNGFR) ${ }^{1}$ in the remaining nephrons increases dramatically (1-9). This increase in filtration rate imposes an increased reabsorptive burden on the residual nephrons, if electrolyte and acid-base balance is to be preserved. Previous studies have shown that the proximal tubule has a high capacity to increase fluid and bicarbonate reabsorption when SNGFR is increased acutely in normal rats $(10,11)$. This high reabsorptive capacity appears to reside primarily in the early portion of the proximal tubule (11). Given the high SNGFR in the residual nephrons of the remnant kidney, one might anticipate therefore that fluid and bicarbonate reabsorption would increase as well, particularly in the early proximal tubule. Although bicarbonate and fluid reabsorption have been measured in the proximal tubule in the remnant kidney model of renal insufficiency by several investigators $(3-6,8,9,12)$, the results have been conflicting. Part of the discrepancy among studies

Address reprint requests to Dr. Maddox, Renal Physiology Laboratory, Division of Nephrology, D308 Given Building, University of Vermont School of Medicine, Burlington, VT 05405.

Received for publication 17 September 1986.

1. Abbreviations used in this paper: APR, absolute proximal reabsorption; ATPase, adenosine triphosphatase; ECF, extracellular fluid; FL, filtered load; FPR, fractional proximal reabsorption; J, reabsorption rate per millimeter per minute; SNGFR, single nephron glomerular filtration rate.

J. Clin. Invest.

(c) The American Society for Clinical Investigation, Inc.

$0021-9738 / 86 / 05 / 1639 / 11 \$ 1.00$

Volume 77, May 1986, 1639-1649 relates to differences in experimental conditions, i.e., extracellular fluid (ECF) volume, age, or species studied. In most studies, fractional fluid and bicarbonate reabsorption in the proximal tubule have been reduced, as compared to control $(3,5,8,9$, 12). As a result, some investigators have concluded that proximal tubular reabsorption is blunted. However, in virtually all studies in which absolute rates of reabsorption have been measured, both fluid and bicarbonate reabsorption have been shown to increase $(5,6,8,9)$. An increase in proximal fluid reabsorption in the isolated perfused nephron of the rabbit remnant kidney has also been observed (13-15). Because this increase in reabsorption was present even under controlled perfusion rates in the isolated nephron, the results were interpreted to indicate that a memory effect existed and that the intrinsic reabsorptive capacity was augmented (14).

In the present study, we have examined proximal tubular reabsorption in the remnant kidney of the Munich-Wistar rat under the steady-state condition of euvolemia (16). We have carried out early as well as late proximal tubular collections, so that we could assess reabsorption as a function of distance from the glomerulus. In addition, we compared the pattern of fluid and bicarbonate reabsorption along the proximal tubule with previous observations in normal two-kidney animals, in which SNGFR and filtered bicarbonate were increased acutely, to determine whether any increase in reabsorptive capacity could be detected in the remnant nephron.

A second issue addressed in this study is the influence of dietary protein intake on proximal tubular function in the remnant kidney. Previous studies have demonstrated that dietary protein restriction prevents progressive glomerulosclerosis in the remnant kidney of the rat $(7,17,18)$. The protective effect of this dietary treatment resides in its ability to prevent the development of greater than normal glomerular capillary pressures and flows (7). Because glomerular capillary hydraulic pressure and plasma flow rate are lower, SNGFR levels are lower after protein restriction for any given degree of nephron ablation (7). Given that protein restriction results in lower SNGFR levels, a relative reduction in tubular reabsorption is necessary if sodium and acid-base balance are to be maintained. In the present study, we have examined whether such adaptative changes in reabsorption occur in the proximal tubule.

Our results indicate that, under conditions of euvolemia, proximal bicarbonate reabsorption in the remnant kidney increases in direct relation to the increase in filtered load; no reduction in fractional reabsorption occurs. Moreover, the pattern of response to the increase in filtered load in both the normal and low protein remnant kidney rats was indistinguishable from that observed when SNGFR is increased acutely by plasma expansion in normal rats (11). The majority of the increase in reabsorptive rate occurred in the first $1-2 \mathrm{~mm}$ of the proximal tubule. Fluid reabsorption in the proximal tubule showed a similar pattern, although fractional reabsorption fell slightly in both remnant kidney groups as compared to control. 


\section{Methods}

All studies were carried out in male Munich-Wistar rats (Simonsen Labs, Gilroy, CA). After several days of adaptation on a low-bulk, normal protein diet, the rats underwent surgery to remove renal tissue. Rats were anesthetized with sodium brevital, a right nephrectomy was performed, and then approximately two thirds of the left kidney was infarcted by ligating branches of the left renal artery. The extent of infarction was estimated from drawings of three views (dorsal, ventral, lateral) of the kidney at the time of infarction. The right kidney was weighed for later estimation of renal hypertrophy (see below). After recovery from anesthesia and surgery, the rats were placed either on a low protein $(6 \%)$ or normal protein (24\%) diet. The diets were made isocaloric by increasing the glucose content of the low protein mix. Both the low protein and normal protein diets were supplemented with $\mathrm{NaCl}(6 \mathrm{meq})$ and $\mathrm{KCl}$ (1 meq) per $12 \mathrm{~g}$ of diet. The rats were fed ad libitum and provided with water to drink until the day of study. Micropuncture measurements were carried out 2-5 wk after preparation of the remnant kidney. 12 remnant kidney rats were studied on the normal protein diet; the average time from surgery to micropuncture was $20 \pm 2 \mathrm{~d}$. 10 remnant kidney rats were studied on the low protein diet; the average time from surgery to micropuncture was $23 \pm 4 \mathrm{~d}$. In addition, six age-matched control animals were studied. These rats were placed on the normal protein diet, and micropuncture measurements were carried out $23 \pm 4 \mathrm{~d}$ later. The average weight at the time of surgical preparation of the remnant kidney was $232 \pm 3 \mathrm{~g}$ in the normal protein remnant kidney rats and $238 \pm 2 \mathrm{~g}$ in the low protein remnant kidney rats. Body weight in the six control rats when first put on the diet was $235 \pm 4 \mathrm{~g}$. The control rats weighed $273 \pm 5$ $\mathrm{g}$ at the time of micropuncture. The normal protein remnant kidney rats lost weight transiently after surgery, but then gained in a normal fashion, and weighed $247 \pm 3 \mathrm{~g}$ at the time of micropuncture $(P<0.001$ vs. control). The low protein remnant kidney rats, by contrast, showed a progressive slow decline in weight from the time of surgery to the time of study, and weighed $209 \pm 3 \mathrm{~g}$ at the time of micropuncture $(P<0.001$ vs. both control and normal protein remnant kidney rats).

The rats were prepared for micropuncture as described previously (19). They were maintained on a small animal ventilator with added $\mathrm{O}_{2}$ to maintain $\mathrm{O}_{2}$ tension $\left(\mathrm{PO}_{2}\right.$ ) at $\sim 100 \mathrm{mmHg}$ (mean $\mathrm{PO}_{2}=100 \pm 4 \mathrm{mmHg}$ in controls, $97 \pm 3 \mathrm{mmHg}$ in the normal protein remnant kidney rats and $114 \pm 5 \mathrm{mmHg}$ in the low protein remnant kidney rats). The animals were maintained in a euvolemic state by infusion of isoncotic rat plasma during surgery ( $1.3 \%$ body weight) from a donor remnant kidney (or control) rat on the same diet (16). Subsequently, the plasma infusion rate was adjusted to maintain the hematocrit at the level seen immediately after induction of anesthesia and insertion of the femoral artery catheter (16). At the end of surgery, $0.4 \mathrm{ml}$ of Ringer's solution containing either $25 \mu \mathrm{Ci}$ (controls) or $12 \mu \mathrm{Ci}$ (remnant kidney rats) of $\left[{ }^{14} \mathrm{C}\right]$ inulin was given as a bolus and was followed by an infusion at $0.84 \mathrm{ml} / \mathrm{h}$ to deliver $52 \mu \mathrm{Ci} / \mathrm{h}$ in control rats and $26 \mu \mathrm{Ci} / \mathrm{h}$ in the remnant kidney rats. After a 45-min equilibration period, timed micropuncture collections were obtained from Bowman's space and from early, mid-, and late proximal tubular sites as described previously $(19,20)$. The puncture sites were marked with a nigrosine-containing saline solution. At the end of the experiment, the kidney was removed, the necrotic tissue was carefully dissected away, and the viable tissue was weighed. The kidney was then digested in $\mathrm{HCl}$ and the micropunctured tubules were dissected out for measurement of length. The total length of the proximal convoluted tubule and/or the distance from the glomerulus to the site of puncture were measured using a calibrated eyepiece micrometer at $\times 72$. In some tubules the outer diameter of the proximal tubule was measured at $\times 144$ after microdissection. Blood and timed urine samples were collected during the experiment for measurement of arterial $\mathrm{pH}, \mathrm{PCO}_{2}, \mathrm{PO}_{2}$, plasma sodium, potassium, and urea nitrogen concentration, urine sodium, potassium and total $\mathrm{CO}_{2}$ excretion, and inulin clearance.

Analytic methods, calculations, and statistics. $\mathrm{Blood} \mathrm{pH}, \mathrm{PCO}_{2}$, and $\mathrm{PO}_{2}$ were measured using a Radiometer blood gas analyzer (Radiometer, Copenhagen). Plasma bicarbonate concentration was calculated using the Henderson-Hasselbalch equation. Sodium and potassium concentrations were measured by flame photometry. Plasma urea nitrogen concentration was measured colorimetrically by the method of Crocker (21). Tubular fluid, Bowman's space, and urine total $\mathrm{CO}_{2}$ concentrations were measured by microcalorimetry (22). The total $\mathrm{CO}_{2}$ concentration measured in tubular fluid was assumed to equal the tubular fluid bicarbonate concentration, because we have shown previously that the $\mathrm{PCO}_{2}$ in nanoliter volume tubular fluid samples falls to zero before microcalorimetry can be performed (19). SNGFR and proximal reabsorption rates were calculated using standard formulas. The filtered load of bicarbonate was calculated as the product of SNGFR and Bowman's space bicarbonate concentration. The degree of hypertrophy of the remnant kidney was calculated from the ratio of the kidney weight at the time of micropuncture to the estimated weight of viable tissue remaining at the time of infarction. The latter value was obtained by multiplying the right kidney weight by the estimated fraction of viable tissue in the left kidney at the time of infarction.

The relationships between reabsorption and distance from Bowman's space shown in Figs. 1 and 3 were fitted to a power curve of the form $y=a x^{b}$, using a computer-based nonlinear least squares search, as described previously (11). Statistical analyses of results were carried out by paired and unpaired analysis of variance, or covariance analysis where appropriate. Results are presented as means \pm standard error.

\section{Results}

Table I presents the arterial blood pressure, hematocrit, and plasma composition in the control and remnant kidney rats. Arterial blood pressure was significantly higher than control only in the normal protein remnant kidney rats. In both groups of remnant kidney rats, arterial hematocrit was significantly reduced as compared with control rats, with the lowest values found in the normal protein remnant kidney group. Arterial $\mathrm{pH}$ was significantly lower than controls in the normal protein remnant kidney group. Plasma bicarbonate concentration was significantly lower than control in both the low protein remnant kidney

Table I. Arterial Pressure and Blood Composition

\begin{tabular}{llllllllll}
\hline Group & $\overline{\mathrm{AP}}$ & $\mathrm{Hct}$ & $\mathrm{pH}$ & $\mathrm{PCO}_{2}$ & {$\left[\mathrm{HCO}_{3}\right]$} & {$[\mathrm{Na}]$} & {$[\mathrm{K}]$} & PUN & [Plasma protein] \\
\hline & $\mathrm{mmHg}$ & vol \% & & $m m H g$ & $m M$ & $m M$ & $m M$ & $m g / d l$ & $g / d l$ \\
Control $(n=6)$ & $112 \pm 2$ & $49.2 \pm .7$ & $7.43 \pm .01$ & $42.0 \pm 1.1$ & $27.2 \pm .7$ & $147.0 \pm .9$ & $4.36 \pm .13$ & $19.2 \pm 1.9$ & $5.7 \pm .1$ \\
NPRK $(n=12)$ & $128 \pm 5$ & $43.8 \pm .7$ & $7.37 \pm .01$ & $39.5 \pm 1.1$ & $22.3 \pm .7$ & $148.6 \pm .6$ & $4.24 \pm .09$ & $39.5 \pm 3.4$ & $5.6 \pm .1$ \\
$P$ value vs. control & $<.05$ & $<.001$ & $<.01$ & $\mathrm{NS}$ & $<.001$ & $\mathrm{NS}$ & $\mathrm{NS}$ & $<.001$ & $\mathrm{NS}$ \\
LPRK $(n=10)$ & $123 \pm 4$ & $46.0 \pm .9$ & $7.42 \pm .01$ & $38.8 \pm 1.0$ & $24.5 \pm .6$ & $148.5 \pm .7$ & $4.14 \pm .10$ & $20.9 \pm 1.0$ & $5.1 \pm .1$ \\
$P$ value vs. control & $\mathrm{NS}$ & $<.025$ & $\mathrm{NS}$ & $\mathrm{NS}$ & $<.05$ & $\mathrm{NS}$ & $\mathrm{NS}$ & $\mathrm{NS}$ & $<.005$ \\
$P$ value vs. NPRK & $\mathrm{NS}$ & $<.05$ & $<.01$ & $\mathrm{NS}$ & $<.025$ & $\mathrm{NS}$ & $\mathrm{NS}$ & $<.001$ & $<.001$ \\
\hline
\end{tabular}

NPRK, normal protein remnant kidney; LPRK, low protein remnant kidney; $n$, number of rats; $\overline{\mathrm{AP}}$, mean arterial pressure; Hct, arterial hematocrit; PUN, plasma urea nitrogen concentration. Values shown are means \pm SE. 
Table II. GFR, Sodium Excretion, and Kidney Weight

\begin{tabular}{|c|c|c|c|c|c|c|c|}
\hline Group & GFR & $U_{N_{n}} V$ & $\mathrm{FE}_{\mathrm{N}}$ & Expt. L. K. wt. & Rt. K. wt. at surgery & Hypertrophy & Tubule length \\
\hline & $\mu l / \min$ & nmol/min & & $\boldsymbol{g}$ & $g$ & $\%$ & $m m$ \\
\hline Control $(n=6)$ & $1,093 \pm 52$ & $696 \pm 196$ & $0.005 \pm 0.001$ & $1.12 \pm 0.04$ & - & - & $5.4 \pm 0.3$ \\
\hline $\operatorname{NPRK}(n=12)$ & $735 \pm 55$ & $2,262 \pm 370$ & $0.022 \pm 0.005$ & $0.89 \pm 0.06$ & $0.91 \pm 0.02$ & $299 \pm 35$ & $7.3 \pm 0.2$ \\
\hline$P$ value vs. control & $<0.001$ & $<0.025$ & $<0.025$ & $>0.025$ & - & - & $<0.001$ \\
\hline $\operatorname{LPRK}(n=10)$ & $575 \pm 30$ & $1,728 \pm 326$ & $0.023 \pm 0.004$ & $0.53 \pm 0.04$ & $0.95 \pm 0.01$ & $166 \pm 12$ & $6.5 \pm 0.2$ \\
\hline$P$ value vs. control & $<0.001$ & NS & $<0.025$ & $<0.001$ & - & - & $<0.005$ \\
\hline$P$ value vs. NPRK & $<0.025$ & NS & NS & $<0.001$ & NS & $<0.01$ & $<0.05$ \\
\hline
\end{tabular}

NPRK, normal protein remnant kidney; LPRK, low protein remnant kidney; $n$, number of rats; GFR, glomerular filtration rate; $U_{\mathrm{Na}} \mathrm{V}$, sodium excretion rate; $\mathrm{FE}_{\mathrm{Na}}$, fractional sodium excretion rate; Rt. K. wt., right kidney weight; $\mathrm{L}$. $\mathrm{K}$. wt., left kidney weight at the time of micropuncture; hypertrophy, estimated degree of hypertrophy of left kidney from time of surgery to time of micropuncture (see text for method of calculation); tubule length, distance from Bowman's space to the end of the proximal convoluted tubule as measured in 20 tubules in control, 12 tubules in NPRK rats, and 31 tubules in the LPRK group. Values are means \pm SE.

rats $(24.5 \mathrm{mM})$ and the normal protein remnant kidney group $(22.3 \mathrm{mM})$, with the mean value in the latter group also significantly lower than that in the low protein remnant kidney animals. Plasma urea nitrogen was significantly greater in the normal protein remnant kidney rats $(39.5 \mathrm{mg} / \mathrm{dl})$ than in either the control animals $(19.2 \mathrm{mg} / \mathrm{dl})$ or the low protein remnant kidney rats $(20.9 \mathrm{mg} / \mathrm{dl})$. Plasma protein concentration was significantly lower in the low protein remnant kidney rats than in either the controls or the normal protein remnant kidney group.

Clearance observations. Whole kidney GFR was significantly reduced in the remnant kidney rats as compared with control (Table II). In the remnant kidney rats ingesting a normal protein diet, GFR averaged $735 \mu \mathrm{l} / \mathrm{min}$ compared with $1,093 \mu \mathrm{l} / \mathrm{min}$ in control $(P<0.001)$. In the remnant kidney rats ingesting a low protein diet, GFR averaged $575 \mu \mathrm{l} / \mathrm{min}$, a value significantly lower than both control $(P<0.001)$ and normal protein remnant kidney rats $(P<0.025)$. Fractional sodium excretion was significantly higher than control in both remnant kidney groups (Table II). Fractional excretion of potassium was higher than control in the normal protein remnant kidney group $(0.17 \pm 0.02$ vs. $0.09 \pm 0.01, P<0.025$ ). Because potassium excretion was lower in the low protein remnant kidney group than in the normal protein remnant kidney group $(278 \pm 35 \mathrm{nmol} / \mathrm{min}$ vs. $522 \pm 58 \mathrm{nmol} / \mathrm{min}, P<0.005)$, fractional potassium excretion was not significantly increased in these rats. There were no no- table differences in bicarbonate excretion; $>99.5 \%$ of the filtered bicarbonate was reabsorbed in all groups.

Renal hypertrophy. Kidney weights and estimated hypertrophy are also shown in Table II. Left kidney weight in the control rats at the time of the experiment was significantly greater than right kidney weight in either the normal or low protein rats at the time of surgery. Assuming that all kidneys weighed the same $(0.9-0.95 \mathrm{~g})$ when the rats were first placed on the diet, these results indicate an $18-24 \%$ increase in kidney weight owing to normal growth. In the normal protein remnant kidney rats, $64.7 \pm 2.5 \%$ of the left kidney was estimated to be infarcted. At the time of micropuncture left kidney weight was $0.89 \mathrm{~g}$, a value almost three times the estimated weight remaining at the time of infarction. The overall renal hypertrophy in these remnant kidneys was associated with a $33 \%$ increase in the length of the proximal convoluted table as compared with control (Table II, 7.3 vs. $5.4 \mathrm{~mm}, P<0.001$ ). In the low protein remnant kidney rats, $66.8 \pm 2.7 \%$ of the left kidney was estimated to be infarcted. At the time of micropuncture, left kidney weight averaged 0.53 $\mathrm{g}$, a value significantly lower than in the normal protein group $(P<0.01)$. Nonetheless, renal weight at the time of study was $166 \%$ of the value estimated at the time of surgery, indicating significant hypertrophy beyond that expected on the basis of normal growth. The overall hypertrophy was also associated with an increase in the length of the proximal convoluted tubule as

Table III. Single Nephron Function and Proximal Reabsorption*

\begin{tabular}{|c|c|c|c|c|c|c|c|}
\hline Group & SNGFR & $\mathbf{A P R}_{\mathrm{H}_{3} \mathrm{O}}$ & FPR $_{\mathrm{H}>0}$ & $F_{\text {HOS }}$ & $\mathbf{A P R}_{\text {HCOS }}$ & FPR $_{\text {HoOs }}$ & $\mathrm{TF}_{\text {hoOs }}$ \\
\hline & $n l / \min$ & $\mathrm{nl} / \mathrm{min}$ & & pmol/min & pmol/min & & $m M$ \\
\hline Control $(n=5)$ & $40.4 \pm 1.5$ & $19.3 \pm 1.1$ & $0.48 \pm 0.03$ & $1,281 \pm 58$ & $1,121 \pm 35$ & $0.88 \pm 0.02$ & $7.4 \pm 1.2$ \\
\hline NPRK $(n=9)$ & $78.1 \pm 2.0$ & $31.5 \pm 1.2$ & $0.40 \pm 0.02$ & $2,013 \pm 40$ & $1,860 \pm 34$ & $0.92 \pm 0.01$ & $3.1 \pm 0.4$ \\
\hline$P$ value vs. control & $<0.001$ & $<0.001$ & $<0.025$ & $<0.001$ & $<0.001$ & $<0.05$ & $<0.005$ \\
\hline LPRK $(n=8)$ & $58.8 \pm 4.3$ & $23.9 \pm 1.5$ & $0.41 \pm 0.01$ & $1,641 \pm 116$ & $1,430 \pm 94$ & $0.88 \pm 0.02$ & $5.8 \pm 0.7$ \\
\hline$P$ value vs. control & $<0.00 i$ & $<0.05$ & $<0.05$ & $<0.025$ & $<0.025$ & NS & NS \\
\hline$P$ value vs. NPRK & $<0.005$ & $<0.001$ & NS & $<0.005$ & $<0.001$ & $<0.025$ & $<0.01$ \\
\hline
\end{tabular}

NPRK, normal protein remnant kidney rats; LPRK, low protein remnant kidney rats; $\boldsymbol{n}$, number of rats; SNGFR, single nephron glomerular

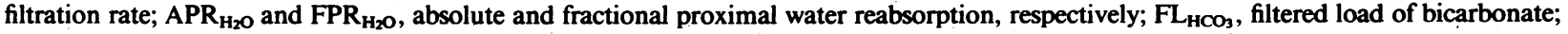
$\mathrm{APR}_{\mathrm{HCO}_{3}}$ and $\mathrm{FPR}_{\mathrm{HCO}_{3}}$, absolute and fractional proximal bicarbonate reabsorption, respectively; $\mathrm{TF}_{\mathrm{HCO}_{3}}$, end-proximal bicarbonate concentration.

* Results obtained from end-proximal collections. 
compared with control (Table III, 6.5 vs. $5.4 \mathrm{~mm}, P<0.01$ ). The increase, however, was less than that observed in the high protein remnant kidney rats $(P<0.05)$. In addition to the increase in length, proximal tubular hypertrophy was evidenced by an increase in diameter. Outer diameter, measured at the time of microdissection, averaged $90 \pm 4 \mu \mathrm{m}$ in 11 tubules of four of the normal protein remnant kidney rats compared with $62 \pm 2 \mu \mathrm{m}$ in eight tubules of two of the control animals $(P$ $<0.001)$. The inner diameter of the nephrons was also increased, perhaps as much as twofold, as determined by visual assessment at the time of micropuncture. However, direct measurements of this parameter were not obtained. Although the observation of an increase in luminal diameter would suggest a large increase in luminal surface area, an estimate of the true change in total luminal surface area would require a measurement of the surface area of the brush border. Such information was not obtained by the techniques used in the present study.

Micropuncture results. Table III summarizes the micropuncture observations made at late proximal tubular sites. SNGFR was significantly higher in both remnant kidney groups as compared with control, averaging $78.1 \mathrm{nl} / \mathrm{min}$ in the normal protein remnant kidney rats and $58.8 \mathrm{nl} / \mathrm{min}$ in the low protein remnant kidney rats, as compared with $40.4 \mathrm{nl} / \mathrm{min}$ in controls. The filtered load of $\mathrm{HCO}_{3}^{-}\left(\mathrm{FL}_{\mathrm{HCO}_{3}}\right)$ also increased notably in the remnant kidney groups as compared with control. In the normal protein remnant kidney rats $\mathrm{FL}_{\mathrm{HCO}_{3}}$ averaged 2,013 $\mathrm{pmol} / \mathrm{min}$, as compared with $1,281 \mathrm{pmol} / \mathrm{min}$ in controls. In the low protein remnant kidney rats $\mathrm{FL}_{\mathrm{HCO}_{3}}$ averaged 1,641 $\mathrm{pmol} / \mathrm{min}$. In response to the increase in load, proximal $\mathrm{HCO}_{3}$ reabsorption $\left(\mathrm{APR}_{\mathrm{HCO}_{3}}\right)$ increased in both remnant kidney groups. In the normal protein remnant kidney rats, $A P R_{\mathrm{HCO}_{3}}$ averaged $1,860 \mathrm{pmol} / \mathrm{min}$, as compared with $1,121 \mathrm{pmol} / \mathrm{min}$ in controls. In the low protein remnant kidney rats, $A \mathrm{PR}_{\mathrm{HCO}_{3}}$ was intermediate in value, $1,430 \mathrm{pmol} / \mathrm{min}$. The fraction of filtered $\mathrm{HCO}_{3}$ reabsorbed at the end of the accessible proximal tubule in the normal protein remnant kidney rats $(0.92)$ was significantly higher than in either the low protein remnant kidney rats $(\mathbf{0 . 8 8 )}$ or the control rats $(\mathbf{0 . 8 8 )}$. End-proximal bicarbonate concentration was significantly lower in the normal protein remnant kidney rats than in either the age-matched control animals or the low protein remnant kidney groups. Fluid reabsorption was higher in both remnant kidney groups, averaging $31.5 \mathrm{nl} / \mathrm{min}$ in the normal protein remnant kidney rats, and $23.9 \mathrm{nl} / \mathrm{min}$ in the low protein remnant kidney rats, as compared with $19.3 \mathrm{nl} / \mathrm{min}$ in controls. In contrast to $\mathrm{HCO}_{3}$ reabsorption, however, fractional fluid reabsorption $\left(\mathrm{FPR}_{\mathrm{H}_{2} \mathrm{O}}\right)$ was slightly but significantly lower in both remnant kidney groups as compared with controls.

Pattern of bicarbonate reabsorption along the tubule. In Fig. 1, we have plotted bicarbonate reabsorption as a function of distance from the glomerulus to the site of collection in rats with comparable filtered loads. For this assessment, we have grouped our observations according to different ranges of $\mathrm{FL}_{\mathrm{HCO}_{3}}: 1,200-$ $1,600 \mathrm{pmol} / \mathrm{min}(A), 1,600-2,000 \mathrm{pmol} / \mathrm{min}(B)$, and 2,000 $2,400 \mathrm{pmol} / \mathrm{min}(C)$. In $D$, three $\mathrm{FL}_{\mathrm{HCO}_{3}}$ ranges in which insufficient data points were obtained in the remnant kidney rats to provide complete curves are shown; solid symbols, $\mathrm{FL}_{\mathrm{HCO}_{3}}$ range $=800-1,200 \mathrm{pmol} / \mathrm{min}$; open symbols, $2,400-2,800 \mathrm{pmol} / \mathrm{min}$; and half-filled symbols, 2,800-3,400 pmol/min. Each point in Fig. 1 represents a single tubular fluid collection (triangles, agematched control rats; circles, low protein remnant kidney rats; squares, normal protein remnant kidney rats). For the three lower

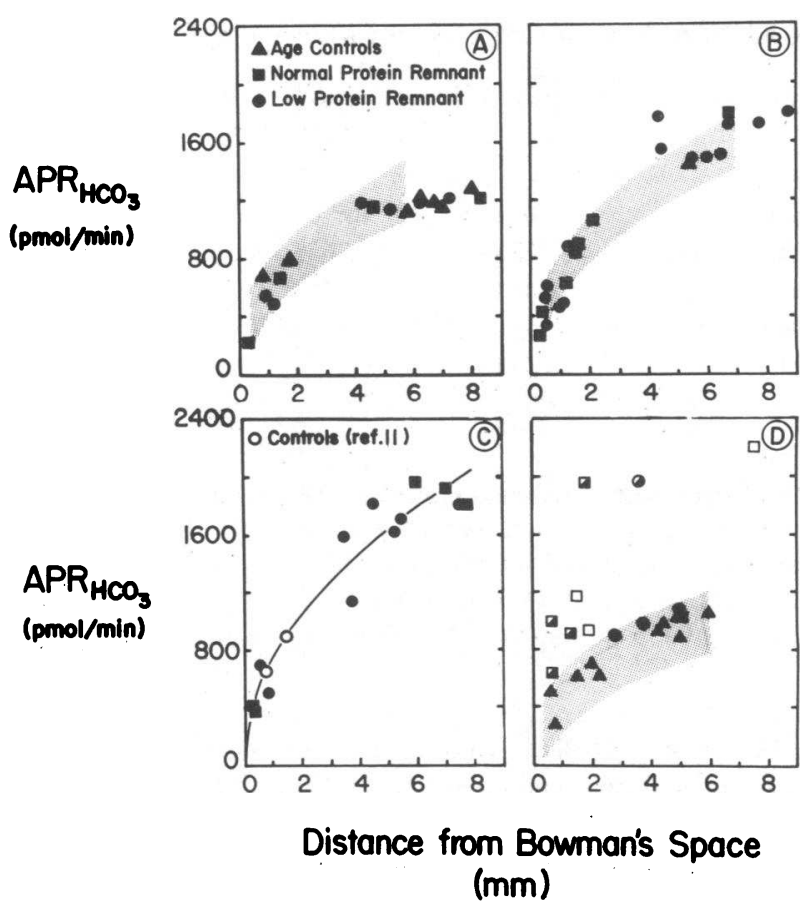

Figure 1. Absolute proximal bicarbonate reabsorption $\left(\mathrm{APR}_{\mathrm{HCO}_{3}}\right)$ as a function of distance from Bowman's space for collections having different ranges of filtered bicarbonate load $\left(\mathrm{FL}_{\mathrm{HCO}_{3}}\right)$ in low and normal protein remnant kidney rats and in age-matched controls. The ranges of $\mathrm{FL}_{\mathrm{HCO}_{3}}$ shown are: $(A) 1,200-1,600 \mathrm{pmol} / \mathrm{min} ;(B) 1,600-2,000$ $\mathrm{pmol} / \mathrm{min}$; $(C)$ 2,000-2,400 pmol/min; (D) solid symbols, $800-1,200$ $\mathrm{pmol} / \mathrm{min}$; open symbols, $2,400-2,800 \mathrm{pmol} / \mathrm{min}$; and half-filled symbols, $2,800-3,400 \mathrm{pmol} / \mathrm{min}$. Triangles depict values obtained from age-matched control rats, squares are from normal protein remnant kidney rats, and circles (except for $\circ C$ ) are from low protein remnant kidney rats. Also shown in $A, B$, and $D$ are the $95 \%$ confidence bands for data from normal two-kidney rats of a previous study in which $\mathrm{FL}_{\mathrm{HCO}_{3}}$ was varied acutely by varying plasma volume (11). Only two values in the $2,000-2,400 \mathrm{pmol} / \mathrm{min} \mathrm{FL}_{\mathrm{HCO}_{3}}$ range were available from that study ( $O$ in $C$ ). The form of the equation used to depict the relationship between $\mathrm{APR}_{\mathrm{HCO}_{3}}$ and distance from Bowman's space (D) was $\mathrm{APR}_{\mathrm{HCO}_{3}}=a(D)^{b}$. The values for $a$ and $b$ are given in Table IV.

ranges of $\mathrm{FL}_{\mathrm{HCO}_{3}}$, we include for comparison the $95 \%$ confidence bands (shaded regions) for the relationship found in normal rats in which $\mathrm{FL}_{\mathrm{HCO}_{3}}$ was varied acutely by changes in SNGFR induced by hydropenia, euvolemia, plasma expansion, or aortic constriction (11). The equations relating $A \mathrm{AR}_{\mathrm{HCO}_{3}}$ to distance from Bowman's space are presented in Table IV. As can be seen, the pattern of reabsorption is similar in the remnant kidney rats to that observed in the acute studies. In both settings, the majority of the filtered load is reabsorbed by the end of the first $2 \mathrm{~mm}$ of the tubule. In the present study, $57.5 \%$ is reabsorbed by the end of $2 \mathrm{~mm}$ in the $1,200-1,600$ range, as compared with $58.4 \%$ in the acute studies. In the $1,600-2,000$ range, $52.3 \%$ is reabsorbed in the first $2 \mathrm{~mm}$ in the present studies as compared with $51.2 \%$ in the acute studies. Although insufficient data from acute studies are available for comparison at filtered loads of 2,000-2,400 $\mathrm{pmol} / \mathrm{min}$, a similar pattern is observed (Fig. $1 C$ ). In these animals, $47.3 \%$ of the filtered $\mathrm{HCO}_{3}$ is reabsorbed at the end of the first $2 \mathrm{~mm}$. The data obtained in both the low protein remnant kidney rats and the age-matched control rats with filtered loads of $800-1,200 \mathrm{pmol} / \mathrm{min}$ (Fig. $1 \mathrm{D}$ ) also fall within the $95 \%$ 
Table IV. Regression Equations for Relationships in Figs. 1-4

\begin{tabular}{|c|c|c|c|c|c|c|}
\hline & \multirow[b]{2}{*}{ Group } & \multicolumn{2}{|c|}{ Coefficients } & \multirow[b]{2}{*}{$r$} & \multirow[b]{2}{*}{ SNGFR } & \multirow[b]{2}{*}{$\mathrm{FL}_{\text {HOH }}$} \\
\hline & & $a$ & $b$ & & & \\
\hline & & & & & nl/min & $\mathrm{pmol} / \mathrm{min}$ \\
\hline \multicolumn{7}{|l|}{ Fig. 1: $\mathrm{APR}_{\mathrm{HCO}_{3}}=a \times(D)^{b}$} \\
\hline $\mathrm{FL}_{\mathrm{HCO}_{3}}$ range $=800-1,200 \mathrm{pmol} / \mathrm{min}$ & control* $^{*}(32)$ & 460 & 0.43 & 0.920 & - & $1,039 \pm 21$ \\
\hline \multirow[t]{2}{*}{$\mathrm{FL}_{\mathrm{HCO}_{3}}$ range $=1,200-1,600 \mathrm{pmol} / \mathrm{min}$} & control* (23) & 600 & 0.43 & 0.956 & - & $1,384 \pm 23$ \\
\hline & remnantł (10) & 550 & 0.42 & 0.966 & - & $1,341 \pm 25$ \\
\hline \multirow[t]{2}{*}{$\mathrm{FL}_{\mathrm{HCO}_{3}}$ range $=1,600-2,000 \mathrm{pmol} / \mathrm{min}$} & control* $^{*}(11)$ & 670 & 0.44 & 0.986 & - & $1,776 \pm 34$ \\
\hline & remnant $¥(21)$ & 650 & 0.50 & 0.964 & - & $1,785 \pm 24$ \\
\hline $\mathrm{FL}_{\mathrm{HCO}_{3}}$ range $=2,000-2,400 \mathrm{pmol} / \mathrm{min}$ & remnant $(13)$ & 745 & 0.49 & 0.961 & - & $2,126 \pm 31$ \\
\hline \multicolumn{7}{|l|}{ Fig. 2: $\mathbf{J}_{\mathrm{HCO}_{3}}=a \times\left(\mathrm{FL}_{\mathrm{HCO}_{3}}\right)+b$} \\
\hline $0.5-1.0 \mathrm{~mm}$ from Bowman's space & $\begin{array}{l}\text { control§ } \\
\quad+\text { remnant } \$ \text { (28) }\end{array}$ & 0.34 & 200 & 0.705 & - & - \\
\hline $1.0-1.5 \mathrm{~mm}$ from Bowman's space & $\begin{array}{l}\text { control§ } \\
\quad+\text { remnant } \ddagger(21)\end{array}$ & 0.22 & 185 & 0.831 & - & - \\
\hline \multicolumn{7}{|l|}{ Fig. 3: $\mathrm{APR}_{\mathrm{H}_{2} \mathrm{O}}=a \times(D)^{b}$} \\
\hline SNGFR range $=30-45 \mathrm{nl} / \mathrm{min}$ & control $^{*}(43)$ & 6.70 & 0.62 & 0.928 & $37.1 \pm 0.5$ & - \\
\hline \multirow[t]{2}{*}{ SNGFR range $=45-60 \mathrm{nl} / \mathrm{min}$} & control* (17) & 8.90 & 0.56 & 0.984 & $50.6 \pm 1.2$ & - \\
\hline & remnant $(14)$ & 8.75 & 0.48 & 0.952 & $53.6 \pm 1.2$ & \\
\hline SNGFR range $=60-75 \mathrm{nl} / \mathrm{min}$ & remnantł (20) & 9.30 & 0.60 & 0.932 & $66.9 \pm 1.0$ & - \\
\hline SNGFR range $=75-90 \mathrm{nl} / \mathrm{min}$ & remnantł (9) & 14.1 & 0.42 & 0.969 & $81.0 \pm 1.5$ & - \\
\hline \multicolumn{7}{|l|}{ Fig. 4: $\mathrm{J}_{\mathrm{H}_{2} \mathrm{O}}=a \times(\mathrm{SNGFR})+b$} \\
\hline $0.5-1.0 \mathrm{~mm}$ from Bowman's space & $\begin{array}{l}\text { control§ } \\
\quad+\text { remnant } \ddagger(28)\end{array}$ & 0.15 & 1.84 & 0.740 & - & - \\
\hline $1.0-1.5 \mathrm{~mm}$ from Bowman's space & $\begin{array}{l}\text { control§ } \\
\quad+\text { remnantł (21) }\end{array}$ & 0.11 & 1.75 & 0.899 & - & - \\
\hline
\end{tabular}

SNGFR, single nephron glomerular filtration rate; $D$, distance from Bowman's space to collection site in mm; $\mathrm{FL}_{\mathrm{HCO}_{3}}$, filtered load of $\mathrm{HCO}_{3}$; $A R_{\mathrm{HCO}_{3}}, \mathrm{APR}_{\mathrm{H}_{2} \mathrm{O}}$, absolute proximal reabsorption rate for $\mathrm{HCO}_{3}$ or $\mathrm{H}_{2} \mathrm{O}$ to the collection site; $\mathrm{J}_{\mathrm{HCO}_{3}}, \mathrm{~J}_{\mathrm{H}_{2} \mathrm{O}}, \mathrm{HCO}_{3}$ or $\mathrm{H}_{2} \mathrm{O}$ reabsorption rate per millimeter per minute. The values for SNGFR and $\mathrm{FL}_{\mathrm{HCO}_{3}}$ in the two right-hand columns are the means for each group in the ranges indicated. Numbers in parentheses are number of observations. * Controls are from a previous study in normal two-kidney rats in which the filtered load was varied acutely by varying plasma volume and renal perfusion pressure (11). ‡ The remnant group includes all values from the low protein and normal protein RK rats. $\S$ For these regressions control values include both data from age-matched two-kidney rats in the present study and normal rats from a previous study (11).

confidence bands of the normal rats from our previous study (11).

Fig. 2 shows the relationship between bicarbonate load and reabsorption rate in the early proximal tubule. In this figure, the rate of bicarbonate reabsorption per millimeter per minute $\left(\mathrm{J}_{\mathrm{HCO}_{3}}\right)$ is plotted as a function of $\mathrm{FL}_{\mathrm{HCO}_{3}}$ for all collections obtained between 0.5 and $1.0 \mathrm{~mm}$ from the glomerulus (solid symbols) and between 1.0 and $1.5 \mathrm{~mm}$ from the glomerulus (open symbols). Triangles represent age-matched control rats; circles, low protein remnant kidney rats; and squares, normal protein remnant kidney rats. The values obtained previously (11) in the acute studies (hexagons) are shown again for comparison. The slopes of the relationships obtained for the remnant kidney data were not significantly different from those obtained for the acute studies, and therefore the lines shown in the figure were obtained by linear regression for all data points (Table IV). As can be seen, in both the very early $(0.5-1.0 \mathrm{~mm})$ and early $(1.0-1.5$ $\mathrm{mm}$ ) collections, reabsorption rate increases in direct relation to $\mathrm{FL}_{\mathrm{HCO}_{3}}$, over the range studied. $\mathrm{J}_{\mathrm{HCO}_{3}}$ for collections $0.5-1.0$ $\mathrm{mm}$ from Bowman's space (solid symbols) was significantly greater than that obtained for the collections $1.0-1.5 \mathrm{~mm}$ from Bowman's space (open symbols) at any given $\mathrm{FL}_{\mathrm{HCO}_{3}}(P<0.001$ by covariance analysis). This difference in reabsorption reflects the fact that $\mathrm{J}_{\mathrm{HCO}_{3}}$ decreases exponentially as a function of length along the tubule (Fig. 1).

Pattern of fluid reabsorption along the tubule. In Fig. 3, we have plotted fluid reabsorption $\left(A P R_{\mathrm{H}_{2} \mathrm{O}}\right.$ ) as a function of distance from the glomerulus to the site of collection. For this assessment we have graphed our observations according to different ranges of SNGFR; $45-60 \mathrm{nl} / \mathrm{min}(A), 60-75 \mathrm{nl} / \mathrm{min}(B), 75-90 \mathrm{nl} / \mathrm{min}$ $(C), 30-45 \mathrm{nl} / \mathrm{min}(D$, solid symbols), $90-105 \mathrm{nl} / \mathrm{min}$ ( $D$, open symbols), and 105-120 nl/min ( $D$, half-filled symbols). Each point in Fig. 3 represents a single tubular fluid collection (triangles, age-matched control rats; circles, low protein remnant kidney rats; squares, normal protein remnant kidney rats). For comparison, we have included the $95 \%$ confidence bands for previous observations over the lowest ranges (45-60 nl/min, $A$, and 30-45 nl/min, $D$, solid symbols) in normal rats in which SNGFR was altered acutely (11). The equations relating $A P R_{\mathrm{H}_{2} \mathrm{O}}$ and distance from Bowman's space are presented in 


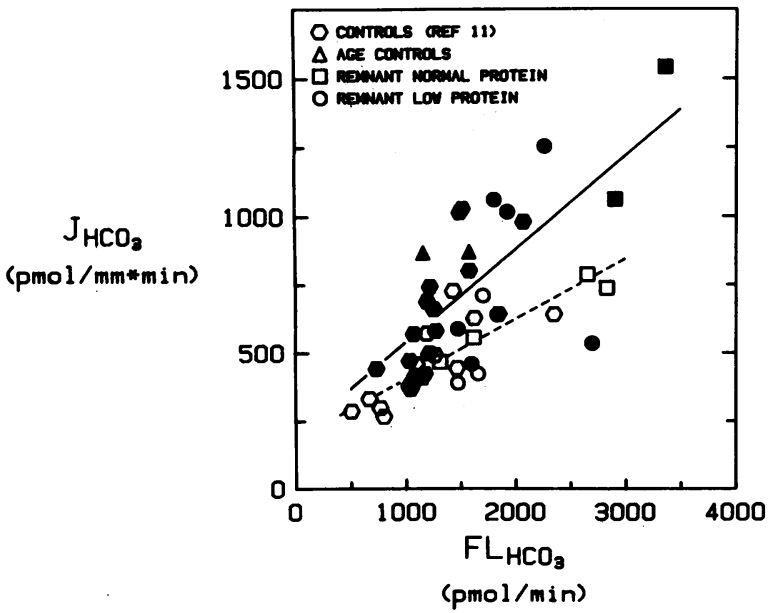

Figure 2. Relationship between bicarbonate reabsorption per millimeter per minute $\left(\mathrm{J}_{\mathrm{HCO}_{3}}\right)$ and filtered load of bicarbonate $\left(\mathrm{FL}_{\mathrm{HCO}_{3}}\right)$ for tubular fluid collections obtained between 0.5 and $1.0 \mathrm{~mm}$ from Bowman's space (solid symbols) and between 1.0 and $1.5 \mathrm{~mm}$ (open symbols) from Bowman's space. Values were obtained in normal (squares) and low protein remnant kidney rats (circles) and in age-matched control rats (triangles). Also shown for comparison are data obtained in a previous study in normal two-kidney rats in which $\mathrm{FL}_{\mathrm{HCO}_{3}}$ was varied acutely by altering plasma volume and renal perfusion pressure (hexagons, Maddox and Gennari [11]). The lines through the data points were obtained by linear regression analysis (Table IV).

Table IV. As can be seen, a similar pattern of reabsorption is seen after either acute or chronic increases in SNGFR over this range. In the range of $60-75 \mathrm{nl} / \mathrm{min}$, three observations from the previous acute study are plotted (Fig. 3 B, open symbols), and again the pattern appears to be the same as in the remnant kidney rats although more data are needed to confirm this prediction. At all levels of SNGFR, water reabsorption increases in response to increases in SNGFR, with virtually all of the increment occurring in the first $1-2 \mathrm{~mm}$ of the proximal tubule.

Fig. 4 shows the relationship between fluid load and reabsorption rate in the early proximal tubule. In this figure water reabsorption per millimeter per minute $\left(\mathrm{J}_{\mathrm{H}_{2} \mathrm{O}}\right)$ is plotted against SNGFR for all collections obtained between 0.5 and $1.0 \mathrm{~mm}$ from Bowman's space (solid symbols), and between 1.0 and 1.5 mm (open symbols) from the glomerulus (triangles, age-matched control rats; circles, low protein remnant kidney rats; squares, normal protein remnant kidney rats). The values obtained in the acute studies are again shown for comparison (hexagons). The relationships found in the remnant kidney rats were not significantly different from those observed in the acute studies in normal rats, and therefore the solid lines shown in the figure were obtained by linear regression for all data points (Table IV). $\mathbf{J}_{\mathrm{H}_{2} \mathrm{O}}$ at any given value of SNGFR was significantly greater from collections $0.5-1.0 \mathrm{~mm}$ from Bowman's space (solid symbols) than that obtained for the collections $1.0-1.5 \mathrm{~mm}$ from the glomerulus (open symbols, $P<0.005$ by covariance analysis). Thus fluid reabsorption in the early proximal tubule increased in direct relation to the increases in filtered load with the highest rates obtained in segments closest to the glomerulus.

Also shown in Fig. 4 are $\mathrm{J}_{\mathrm{H}_{2} \mathrm{O}}$ values for our mid- to late proximal sites plotted against fluid delivery to these sites (open
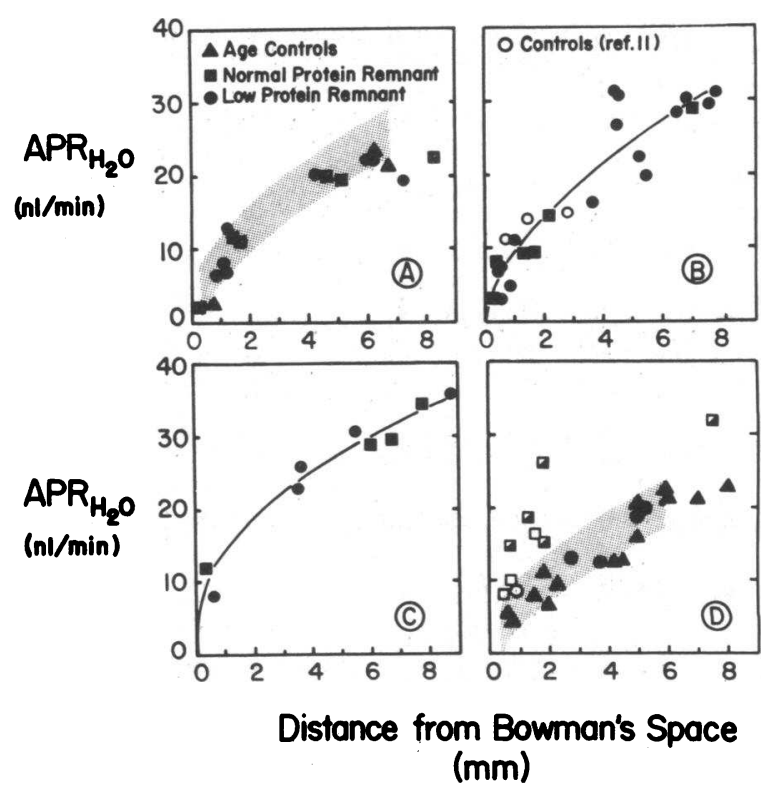

Figure 3. Absolute proximal water reabsorption $\left(A \mathrm{PR}_{\mathrm{H}_{2} \mathrm{O}}\right)$ as a function of distance from Bowman's space for collections having different ranges of single nephron glomerular filtration rate (SNGFR) in low and normal protein remnant kidney rats and in age-matched controls. The ranges of SNGFR shown are: $(A)$ 45-60 nl/min; $(B)$ 60-75 nl/ $\min$; $(C)$ 75-90 nl/min; $(D)$ solid symbols, 30-45 $\mathrm{nl} / \mathrm{min}$; open symbols, $90-105 \mathrm{nl} / \mathrm{min}$; and half-filled symbols, $105-120 \mathrm{nl} / \mathrm{min}$. Triangles depict values obtained from age-matched control rats, squares are from normal protein remnant kidney rats, and circles (except for $O$ in $B)$ are from low protein remnant kidney animals. Also shown by the shaded regions are the $95 \%$ confidence bands for data from normal two-kidney rats with SNGFR values in the $30-45 \mathrm{nl} / \mathrm{min}$ range $(D)$ and the 45-60 nl/min range $(A)$ as well as three data points from normal rats with SNGFR values in the $60-75 \mathrm{nl} / \mathrm{min}$ range ( $O$ in $B$, Maddox and Gennari [11]). The form of the equations depicting the relationship between $\mathrm{APR}_{\mathrm{H}_{2} \mathrm{O}}$ vs. distance from Bowman's space $(D)$ was $\mathrm{APR}_{\mathrm{H}_{2} \mathrm{O}}=a(D)^{b}$. Values for $a$ and $b$ are given in Table IV.

symbols in the shaded area). These values were calculated for the 3-4, 4-5, and 5-6-mm segments from equations describing the RK data shown in each of the three panels of Fig. 3 (see Table IV). For the relationship in each panel, calculated fluid delivery and $\mathbf{J}_{\mathrm{H}_{2} \mathrm{O}}$ were averaged over the three segments, and these mean values are shown as open circles in Fig. 4. For comparison, $\mathrm{J}_{\mathrm{H}_{2} \mathrm{O}}$ vs. fluid delivery to these same sites (3-6 $\mathrm{mm}$ from Bowman's space) in normal two-kidney rats obtained previously (11) are denoted as open triangles $(\Delta)$. Also shown $(\square)$ are the mean values of $\mathrm{J}_{\mathrm{H}_{2} \mathrm{O}}$ vs. perfusion rate from microperfusion studies of Alpern and co-workers (23). The contrast between these mid-to-late proximal tubule observations and our early proximal measurements is examined in the Discussion.

\section{Discussion}

The present study indicates that proximal fluid and bicarbonate reabsorption rates increase adaptively in the functioning nephrons of the remnant kidney. In rats fed a normal protein diet, SNGFR and $\mathrm{FL}_{\mathrm{HCO}_{3}}$ increased to the greatest extent, as did proximal reabsorption. In rats in which dietary protein was restricted, a much smaller increment in SNGFR and $\mathrm{FL}_{\mathrm{HCO}_{3}} \mathrm{OC}-$ 


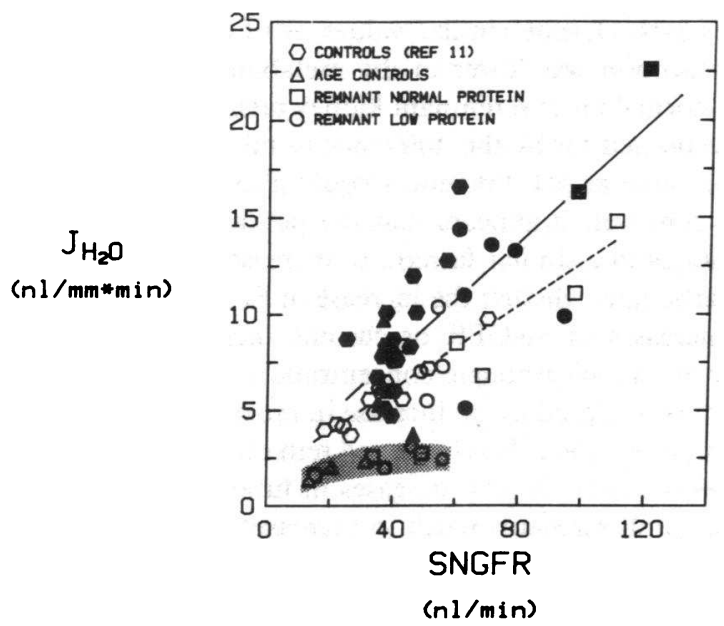

Figure 4. Relationship between water reabsorption per millimeter per minute $\left(\mathrm{J}_{\mathrm{H}_{2} \mathrm{O}}\right)$ and SNGFR. Data shown by the solid symbols are from collections obtained 0.5-1.0 mm from Bowman's space in low and normal protein remnant kidney rats and in age-matched controls, whereas data depicted by the open symbols were obtained from collections 1.0-1.5 mm from Bowman's space. Also shown are data from a previous study in normal two-kidney rats in which SNGFR was varied acutely by altering plasma volume and renal perfusion pressure (11). The lines drawn through the data points were obtained by regression analysis (Table IV). Also shown by open symbols under the shaded area are data from observations in the mid-to-late proximal tubule. The open squares ( $\square$ ) in the shaded region are from microperfusion studies of Alpern and co-workers (23). For these points perfusion rate rather than SNGFR is plotted vs. $\mathbf{J}_{\mathrm{H}_{2} \mathrm{O}}$. Data shown by open circles (0) in the shaded region are from mid-to-late proximal tubule data in the low and normal protein remnant kidney rats. For these points, fluid delivery rather than $\mathrm{SNGFR}$ is plotted vs. $\mathrm{J}_{\mathrm{H}_{2} \mathrm{O}}$. Fluid delivery and reabsorption are calculated from equations shown in Table IV (see text for calculations). The open squares ( $\square$ ) in the shaded region are values calculated in a similar manner from mid-to-late proximal collections in normal two-kidney rats (11).

curred, and proximal reabsorptive rates were proportionately reduced as compared with the normal protein rats. In both groups the greatest adaptive alterations in reabsorption occurred in the early proximal tubule. In the subsequent discussion, we will turn our attention first to proximal tubular bicarbonate reabsorption, and then to proximal tubular fluid reabsorption.

Proximal tubular bicarbonate reabsorption has been measured in the residual nephrons of the remnant kidney in four prior studies. In the first such study reported, absolute bicarbonate reabsorption was not measured but fractional reabsorption fell from $89 \%$ to $79 \%$ (12). These investigators concluded that bicarbonate reabsorption in the proximal tubule was blunted in the remnant kidney. In the subsequent three studies, absolute rates of proximal bicarbonate reabsorption were measured and uniformly found to be increased $(6,8,9)$. The increase above control was variable, however, and fractional reabsorption fell in two $(8,9)$ of the three studies. Although a reduction in fractional reabsorption might, at first glance, support the notion that proximal bicarbonate reabsorptive capacity was diminished in the remnant kidney, the observations might also be explained by the experimental setting. In two of the three studies, acute ECF volume expansion was induced with hypertonic alkali-con- taining solutions during the period of study $(6,8)$. Despite ECF volume expansion, fractional reabsorption did not fall in one of these studies (6). In the third study, proximal bicarbonate reabsorption was studied in immature rats under conditions of hydropenia (8). The results of the present study are consistent with previous studies, in that absolute bicarbonate reabsorption increased in the proximal tubule. Fractional reabsorption was either unchanged from control (low protein remnant kidney group) or actually increased (high protein remnant kidney rats) despite the fact that the filtered load virtually doubled in the latter group. It seems probable, therefore, that the reduction in fractional reabsorption observed in some previous studies relates to physiologic factors influencing proximal bicarbonate reabsorption rather than any intrinsic limitation on transport.

The correlation between filtered load of bicarbonate and proximal reabsorptive rate in the remnant kidney is illustrated by the difference in reabsorption in the rats ingesting low or normal protein diets. The number of functioning nephrons in these groups is similar (based on the degree of infarction), yet the reabsorptive burden for bicarbonate differs significantly owing to the difference in SNGFR. Despite the difference in $\mathrm{FL}_{\mathrm{HCO}_{3}}$, fractional bicarbonate reabsorption differed only slightly in the two groups, and was actually higher in the group with the higher filtered load. Thus, absolute bicarbonate reabsorption differed in almost direct proportion to the difference in filtered load. Moreover, the pattern of reabsorption along the nephron for any given $\mathrm{FL}_{\mathrm{HCO}_{3}}$ was indistinguishable in the two remnant kidney groups.

The load dependence of bicarbonate reabsorption in the remnant nephron occurs largely in the early proximal tubule. As shown in Fig. 2, $\mathrm{J}_{\mathrm{HCO}_{3}}$ in the first $0.5-1.0 \mathrm{~mm}$ of the proximal tubule increased from $\sim 676$ to $\sim 1,390 \mathrm{pmol} / \mathrm{mm} \cdot \min$ when $\mathrm{FL}_{\mathrm{HCO}_{3}}$ increased from 1,400 to $3,500 \mathrm{pmol} / \mathrm{min}$. There was only a small shift in bicarbonate reabsorption to later segments of the nephron when $\mathrm{FL}_{\mathrm{HCO}_{3}}$ increased (Fig. 1); $\sim 60 \%$ of the $\mathrm{HCO}_{3}^{-}$reabsorbed in the accessible proximal tubule was recaptured in the first $2 \mathrm{~mm}$ in the $1,200-1,600 \mathrm{pmol} / \mathrm{min} \mathrm{FL}_{\mathrm{HCO}_{3}}$ range, and $\sim 55 \%$ was recaptured in the $2,000-2,400 \mathrm{pmol} / \mathrm{min}$ $\mathrm{FL}_{\mathrm{HCO}_{3}}$ range.

In vivo microperfusion studies in the normal rat have suggested that proximal bicarbonate reabsorptive capacity is limited to $\sim 200 \mathrm{pmol} / \mathrm{mm} \cdot \min (23,24)$. However, we have recently demonstrated that this limitation is most likely confined to later segments of the proximal convoluted tubule (11). Early proximal tubule bicarbonate reabsorptive capacity was found to be much greater than $200 \mathrm{pmol} / \mathrm{mm} \cdot \mathrm{min}$ when the filtered load of bicarbonate was increased acutely by increasing SNGFR (11). Primarily because of the high reabsorptive capacity of the early proximal tubule (11), total proximal bicarbonate reabsorption increases as a function of filtered load in the normal rat when SNGFR is increased acutely $(10,11,19)$. Based on these observations, proximal bicarbonate reabsorption might be expected to increase in the remnant kidney independent of any anatomic change. To assess whether the response of the tubule to increased filtered load was different in the remnant kidney from that observed acutely, we have compared the pattern of reabsorption as a function of length along the tubule in Fig. 1. As can be seen, for any given $\mathrm{FL}_{\mathrm{HCO}_{3}}$ up to $2,000 \mathrm{pmol} / \mathrm{min}$, no difference was noted in the acute studies as compared with the remnant kidney. At $\mathrm{FL}_{\mathrm{HCO}_{3}}$ levels $>2,000 \mathrm{pmol} / \mathrm{min}$, insufficient acute data in normal animals are available for comparison, but the pattern 
of reabsorption at this level in the remnant kidney rats is similar to that observed at the lower filtered loads. The similarity in response is also apparent when one examines the relationship between $\mathrm{FL}_{\mathrm{HCO}_{3}}$ and $\mathrm{J}_{\mathrm{HCO}_{3}}$ in the early proximal tubule. No difference was noted in the slope of this relationship when the remnant kidney rats were compared with the acute studies.

In the remnant kidney, the proximal tubule increases both in diameter and length, and this change has been implicated to account for increased fluid reabsorptive capacity (13). In the present study, the length of the proximal convoluted tubule increased by over $30 \%$ in the normal protein remnant kidney rats. In addition, the outer diameter of the proximal tubule increased by $45 \%$ in these animals, accompanied by a large increase in luminal diameter. Thus, the total surface area available for reabsorption increased notably. The increase in length was intermediate in the low protein remnant kidney rats, and in these animals, reabsorptive rate was also intermediate in magnitude between control and the normal protein remnant kidney rats. Such changes in surface area for reabsorption could well be a requirement for bicarbonate reabsorption to increase to the extent it does in the remnant kidney. However, given the similar pattern of reabsorption as a function of length at any given filtered load between controls and remnant kidney rats, it seems unlikely that hypertrophy is the sole factor responsible for the high rate of proximal bicarbonate reabsorption in the residual nephrons of the remnant kidney. One cannot, of course, exclude a contribution of increased tubular size to overall reabsorption. It is apparent from Fig. 1 that for any given filtered load, some additional bicarbonate reabsorption occurs as a result of the increase in length. If one uses the equations relating $\mathrm{APR}_{\mathrm{HCO}_{3}}$ to distance from Bowman's space (Table IV) one can estimate the contribution of the increase in tubular length to proximal reabsorption. Based on such a calculation, the 7.3-mm remnant kidney tubule in the normal protein rats could have reabsorbed $\sim$ 150-270 $\mathrm{pmol} / \mathrm{min}$ more than the 5.4-mm control tubule, depending on the range of filtered load used. This calculated difference can account for $20-37 \%$ of the mean difference in $\mathrm{APR}_{\mathrm{HCO}_{3}}$ between the control and normal protein remnant kidney rats. ${ }^{2}$

We have recently also examined the pattern of bicarbonate reabsorption along the nephron in rats with chronic metabolic alkalosis, a setting in which $\mathrm{FL}_{\mathrm{HCO}_{3}}$ is increased by increasing plasma bicarbonate concentration rather than SNGFR (25). In these studies $\mathrm{FL}_{\mathrm{HCO}_{3}}$ increased to levels as high as 2,400 pmol/ min, and the pattern of bicarbonate reabsorption along the nephron even at these high loads was nearly identical to that seen in the remnant kidney rats of the present study. In the metabolic alkalosis rats, proximal tubular length increased as well, although not to the extent seen in the normal protein rem-

2. This estimate assumes that the increased reabsorptive surface area has late proximal reabsorptive characteristics. Support for this assumption is the concordance between the control and remnant kidney data shown in Figs. 1 and 3. Excluded from this analysis, however, are changes in surface area per millimeter of length owing to the observed increase in luminal diameter. Whether increases in actual brush border membrane surface area per millimeter of length also occur in the remnant kidney is unknown. nant kidney rats. Despite similar values of $\mathrm{FL}_{\mathrm{HCO}_{3}}$, fractional $\mathrm{HCO}_{3}$ reabsorption was lower in the metabolic alkalosis rats than in the normal protein remnant kidney rats. This difference could be accounted for by the difference in tubular length, but other factors such as pH differences could also be responsible. In general, however, it appears that the proximal convoluted tubule responds in a similar fashion to increases in the filtered load of bicarbonate, whether the increase in $\mathrm{FL}_{\mathrm{HCO}_{3}}$ is achieved by acute increases in SNGFR or chronic increases in either SNGFR or plasma bicarbonate concentration.

The factors that produce an increase in proximal bicarbonate reabsorption when SNGFR is increased remain obscure. Alpern et al. (23) demonstrated that increases in luminal flow rate in perfused nephron segments result in increases in the mean luminal bicarbonate concentration. Thus later nephron segments are exposed to a higher bicarbonate concentration and presumably a lower transmembrane hydrogen ion concentration gradient. However, in their study only a small percentage of the observed changes in bicarbonate reabsorption could be accounted for by the changes in luminal bicarbonate concentration. Flow-induced alterations in bicarbonate delivery appeared to induce some other concentration-independent changes in bicarbonate reabsorption. In the present study, the normal protein remnant kidney rats actually had the lowest mean luminal bicarbonate concentration (owing to the lower plasma bicarbonate concentration), yet bicarbonate reabsorption was greatest in these rats. Thus, an increase in mean luminal bicarbonate concentration owing to the increased SNGFR cannot be invoked to explain the increase in reabsorption in these rats.

One possible explanation for the increase in reabsorption as

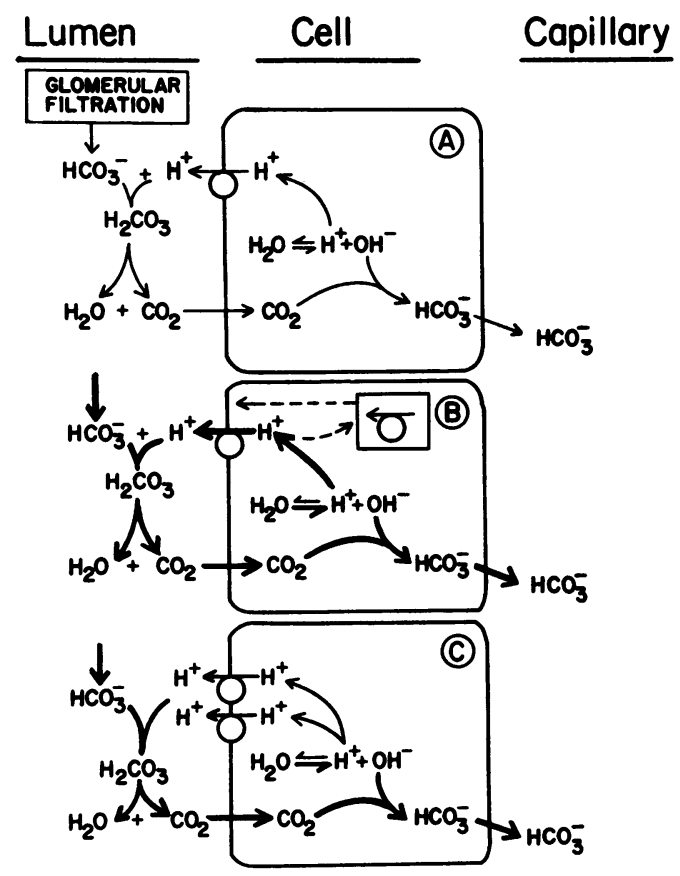

Figure 5. Hypothetical mechanism for increased proximal tubular bicarbonate reabsorption after an increase in the filtered load of bicarbonate. 
filtered load is increased is a feedback-induced increase in $\mathrm{Na}^{+} /$ $\mathrm{H}^{+}$exchangers or proton translocating adenosine triphosphatase (ATPase) pumps in the luminal brush border, as depicted in Fig. 5. Fig. $5 A$ depicts the normal case for reabsorption of filtered bicarbonate. After an acute increase in $\mathrm{HCO}_{3}^{-}$load, created either by an increase in SNGFR or an increase in plasma bicarbonate concentration, secreted hydrogen ions encounter more bicarbonate, and thus generate more $\mathrm{CO}_{2}$ in the tubular lumen. Because this $\mathrm{CO}_{2}$ rapidly enters the cell, more hydrogen ions are released in the cell as hydroxyl ions combine with the $\mathrm{CO}_{2}$, a reaction facilitated by carbonic anhydrase (Fig. $5 \mathrm{~B}$ ). A transient increase in $\mathrm{H}^{+}$occurring as a result of this reaction might not only provide more substrate for $\mathrm{H}^{+}$secretion via existing pumps, but might also stimulate the insertion of additional pumps into the brush border membrane (box in $B$ ). This effect would further increase the capacity to reabsorb bicarbonate and help maintain a reabsorptive reserve capacity (Fig. $5 C$ ). Further studies are required to examine this possibility. However, changes in proximal tubular hydrogen ion secretory capacity occurring in response to changes in the filtered load of bicarbonate and/or $\mathrm{PCO}_{2}$ have been demonstrated in a variety of studies. Studies in the remnant kidney in both the $\operatorname{dog}(26)$ and rabbit (27) have demonstrated a significant increase in sodium-hydrogen exchange activity in brush border membrane vesicles. Recent studies have provided evidence in support of the ability of the proximal tubule to adapt even more acutely to a signal for increased bicarbonate reabsorption. Within 24 h of uninephrectomy, sodium-hydrogen exchange activity increases significantly in brush border membrane vesicles obtained from rat kidneys (28). The degree of the increase correlated with changes in GFR and hence the filtered load of bicarbonate. Even more striking, vesicles presumed to contain hydrogen ion translocating ATPase appear to insert into the luminal membrane of the epithelium of the proximal straight tubule within $1 \mathrm{~min}$ after exposure to an increase in $\mathrm{PCO}_{2}$ and luminal bicarbonate delivery (29). Both of these results indicate that tubular hydrogen ion secretory capacity can change much more rapidly than it takes for tubular hypertrophy to develop. Thus, the similarity between the pattern of bicarbonate reabsorption in normal kidneys after acute increases in SNGFR (11) and the pattern observed in remnant kidneys in the present study as well as those obtained in chronic metabolic alkalosis (25) might be reconciled by such a feedback hypothesis.

Fluid reabsorption in the proximal tubule has been measured in the residual nephrons of the remnant kidney both under freeflow micropuncture conditions $(3,5,6,8,9)$, and in isolated perfused proximal tubule preparations (13-15). With two exceptions $(3,9)$, these studies have all demonstrated that the absolute rate of fluid reabsorption in the proximal tubule is increased as compared with control in the remnant kidney. At the same time, the fraction of filtered fluid reabsorbed in the proximal tubule has been found uniformly to be reduced. As in the case of previous studies of proximal bicarbonate reabsorption, the micropuncture studies were carried out under a variety of conditions ranging from hydropenia to marked volume expansion. The results of the present study, under conditions of euvolemia, are in agreement with most previous results; absolute proximal fluid reabsorption increased significantly, and fractional fluid reabsorption fell slightly but significantly as compared with age-matched controls. Although there was no difference in dietary salt intake or volume repletion between the control and remnant kidney groups in our study, it is noteworthy that the remnant kidney rats excreted $2 \%$ of the filtered sodium, whereas the control animals excreted $<0.4 \%$. The rats were all fed ad libitum and are nocturnal feeders. An earlier study by one of us (16) has shown that normal rats excrete virtually all the sodium they ingest at night by the following morning. It is conceivable that the remnant kidney rats are unable to excrete their dietary sodium as rapidly. Thus, it is possible that a relative volume expansion was present in these animals, accounting for the slight fall in fractional proximal fluid reabsorption. In accord with this hypothesis, both remnant kidney groups had significantly lower hematocrits than controls (Table I).

Despite the slight fall in fractional reabsorption, proximal fluid reabsorption was highly delivery-dependent, as was the case for bicarbonate reabsorption. Moreover, as shown in Fig. 3, this delivery dependence was manifested primarily in the early proximal tubule. Of the total amount of fluid reabsorbed in the accessible proximal tubule, $55 \%$ is recaptured within the first 2 $\mathrm{mm}$ in remnant kidney rats with SNGFR levels of 45-60 nl/ $\mathrm{min}$ (average, $54 \mathrm{nl} / \mathrm{min}$, Fig. $3 A$ ). In remnant kidney rats with SNGFR levels of $75-90 \mathrm{nl} / \mathrm{min}$ (average, $81 \mathrm{nl} / \mathrm{min}$, Fig. $3 C$ ), $59 \%$ of the fluid reabsorbed in the proximal tubule was recaptured in the first $2 \mathrm{~mm}$. As shown in Fig. $4, \mathrm{~J}_{\mathrm{H}_{2} \mathrm{O}}$ at $0.5-1.0 \mathrm{~mm}$ in the remnant kidney rats increased from 9.3 to $19.8 \mathrm{nl} /$ $\mathrm{mm} \cdot \mathrm{min}$ when SNGFR varied from 50 to $120 \mathrm{nl} / \mathrm{min}$. By contrast, calculated $\mathrm{J}_{\mathrm{H}_{2} \mathrm{O}}$ in the mid-to-late proximal tubule never exceeded $3.1 \mathrm{nl} / \mathrm{min}$, even at fluid delivery rates as high as 56 $\mathrm{nl} / \mathrm{min}$ (Fig. 4, open symbols). Furthermore, it is apparent that $\mathbf{J}_{\mathrm{H}_{2} \mathrm{O}}$ determined by in situ microperfusion in the mid-to-late proximal tubule by Alpern and co-workers (23) is nearly identical to the values obtained by us at comparable delivery rates both in the remnant kidney and in normal rats (11). Thus neither the early or late proximal segments of the remnant kidney appear to reabsorb greater amounts of fluid per millimeter of tubule length than control rats at comparable fluid delivery rates. In the isolated perfused late proximal convoluted tubules of the rabbit remnant kidney, Trizna and co-workers found an increase in reabsorption which was independent of delivery (14). The small increase they found, from 1.0 to $1.7 \mathrm{nl} / \mathrm{mm} \cdot \mathrm{min}$, is not inconsistent with our late proximal data. The maximum calculated value of $3.1 \mathrm{nl} / \mathrm{mm} \cdot \mathrm{min}$ for our $\mathrm{RK}$ data is $\sim 0.6$ $\mathrm{mm} \cdot \mathrm{min}$ greater than that seen in normal rats with SNGFR values of $\sim 40 \mathrm{nl} / \mathrm{min}$. Thus, our data would not exclude a small increase in intrinsic fluid reabsorptive capacity in the late proximal tubule. It is clear, however, that late proximal fluid reabsorption in both normal and remnant kidneys is significantly lower than early proximal fluid reabsorption.

As in the case of bicarbonate reabsorption, the load dependence of fluid reabsorption is demonstrated by comparing the normal protein and low protein remnant kidney rats. In the latter group SNGFR is lower, and absolute proximal fluid reabsorption is proportionately reduced as compared to the normal protein rats. Thus, fractional reabsorption is identical in the two groups. Moreover, when fluid reabsorption is plotted as a function of distance from the glomerulus for any given filtered load, or as a function of $\mathrm{FL}_{\mathrm{H}_{2} \mathrm{O}}$ in the early proximal tubule, the response of the proximal tubule is the same regardless of protein intake (Figs. 3 and 4). 
The load dependence of fluid reabsorption in the early proximal tubule parallels the load dependence for bicarbonate reabsorption. When comparison was possible, the pattern of fluid reabsorption in the remnant kidney proximal tubule was indistinguishable from that seen after an acute increase in SNGFR in the normal kidney (Fig. 3). Using the equations relating fluid reabsorption to length along the tubule (Table IV), 25-40\% of the increase in water reabsorption can be accounted for by an increase in length from 5.4 to $7.3 \mathrm{~mm}$ (control vs. normal protein remnant kidney tubule lengths). The parallel results for fluid and bicarbonate reabsorption in the present study are not surprising, given the evidence that sodium and bicarbonate reabsorption are closely linked in the proximal tubule (30). An adaptive response characterized by an increase in the number or activity of $\mathrm{Na}^{+}-\mathrm{H}^{+}$exchangers could account, at least in part, for these results.

In summary, these studies indicate that the residual nephrons of the remnant kidney exhibit a normal physiologic response to the increase in SNGFR and $\mathrm{FL}_{\mathrm{HCO}_{3}}$ that occurs. As in the case of the proximal tubule in the normal kidney, a strong load dependence of fluid and bicarbonate reabsorption is present. These studies, in combination with previous studies from our laboratory, indicate that the pattern of proximal bicarbonate reabsorption is similar regardless of whether $\mathrm{FL}_{\mathrm{HCO}_{3}}$ is varied by acute (11) or chronic alterations in SNGFR, or by chronic alterations in plasma bicarbonate concentration (25). The increase in proximal tubular length augments this response. A similar major role for SNGFR in determining the pattern of fluid reabsorption in the proximal tubule is evident in both acute and chronic settings, with an additional factor of tubular hypertrophy contributing to the response seen in the remnant kidney. The factor that may link all of these findings is an adaptive response characterized by an increase in sodium-hydrogen exchange or $\mathrm{H}^{+}$-ATPase in the proximal tubule. Further studies are required to test this hypothesis, and to determine the mechanism by which the tubule is signalled to increase reabsorption.

\section{Acknowledgments}

The authors are grateful to William D. Barnes and Vidya Gadamasetti for expert technical assistance and to Donna C. Bryan for preparation of this manuscript.

This work was supported by National Institutes of Health grants AM-30872 and AM-26699. D. A. Maddox is the recipient of a Research Career Development Award 1-K04-AM-01057 of the National Institutes of Health. F. C. Famiano was the recipient of a Fellowship award from the Vermont Heart Association.

\section{References}

1. Bricker, N. S., S. Klahr, and R. E. Rieselbach. 1964. The functional adaptation of the diseased kidney. I. Glomerular filtration rate. J. Clin. Invest. 43:1915-1921.

2. Hayslett, J. P., M. Kashgarian, and F. H. Epstein. 1969. Mechanism of change in the excretion of sodium per nephron when renal mass is reduced. J. Clin. Invest. 48:1002-1006.

3. Schultze, R. G., F. Weisser, and N. S. Bricker. 1972. The influence of uremia on fractional sodium reabsorption by the proximal tubule of rats. Kidney Int. 2:59-65.
4. Deen, W. M., D. A. Maddox, C. R. Robertson, and B. M. Brenner. 1974. Dynamics of glomerular ultrafiltration in the rat. VII. Response to reduced renal mass. Am. J. Physiol. 227:556-562.

5. Weber, H., K.-Y. Lin, and N. S. Bricker. 1975. Effect of sodium intake on single nephron glomerular filtration rate and sodium reabsorption in experimental uremia. Kidney Int. 8:14-20.

6. Bank, N., W.-S. Su, and H. S. Aynedjian. 1978. A micropuncture study of $\mathrm{HCO}_{3}$ reabsorption by the hypertrophied proximal tubule. Yale J. Biol. Med. 51:275-282.

7. Hostetter, T. H., J. C. Olson, H. G. Rennke, M. A. Venkatachalam, and B. M. Brenner. 1981. Hyperfiltration in remnant nephrons: a potentially adverse response to renal ablation. Am. J. Physiol. 241 (Renal Fluid Electrolyte Physiol. 10):F85-F93.

8. Buerkert, J., D. Martin, D. Trigg, and E. Simon. 1983. Effect of reduced renal mass on ammonium handling and net acid formation by the superficial and juxtamedullary nephron of the rat. J. Clin. Invest. 71:1661-1675.

9. Wong, N. L. M., G. A. Quamme, and J. H. Dirks. 1984. Tubular handling of bicarbonate in dogs with experimental renal failure. Kidney Int. 25:912-918.

10. Cogan, M. G., D. A. Maddox, M. S. Lucci, and F. C. Rector, Jr. 1979. Control of proximal bicarbonate reabsorption in normal and acidotic rats. J. Clin. Invest. 64:1168-1180.

11. Maddox, D. A., and F. J. Gennari. 1985. Load dependence of $\mathrm{HCO}_{3}$ and $\mathrm{H}_{2} \mathrm{O}$ reabsorption in the early proximal tubule of the MunichWistar rat. Am. J. Physiol. 248 (Renal Fluid Electrolyte Physiol. 17): F113-F121.

12. Lubowitz, H., M. L. Purkerson, D. B. Rolf, F. Weisser, and N. S. Bricker. 1971. Effect of nephron loss on proximal tubular bicarbonate reabsorption in the rat. Am. J. Physiol. 220:457-461.

13. Fine, L. G., W. Trizna, J. J. Bourgoignie, and N. S. Bricker. 1978. Functional profile of the isolated uremic nephron. Role of compensatory hypertrophy in the control of fluid reabsorption by the proximal straight tubule. J. Clin. Invest. 61:1508-1518.

14. Trizna, W., N. Yanagawa, Y. Bar-Khayim, B. Houston, and L. G. Fine. 1981. Functional profile of the uremic nephron. Evidence of proximal tubular "memory" in experimental renal disease. J. Clin. Invest. 68:760-767.

15. Tabei, K., D. J. Levenson, and B. M. Brenner. 1983. Early enhancement of fluid transport in rabbit proximal straight tubules after loss of contralateral renal excretory function. J. Clin. Invest. 72:871881.

16. Maddox, D. A., D. C. Price, and F. C. Rector, Jr. 1977. Effects of surgery on plasma volume and salt and water excretion in rats. $\mathrm{Am}$. J. Physiol. 233 (Renal Fluid Electrolyte Physiol. 2):F600-F606.

17. Kleinknecht, C., I. Salusky, M. Broyer, and M-C. Grubler. 1979. Effects of various protein diets on growth, renal function, and survival of uremic rats. Kidney Int. 15:534-541.

18. Kikuchi, H., T. Matsushita, and K. Hirata. 1983. Improved dietary treatment with low protein and phosphorus restriction in uremic rats. Kidney Int. 24:S254-S258.

19. Maddox, D. A., and F. J. Gennari. 1983. Proximal tubular bicarbonate reabsorption and $\mathrm{PCO}_{2}$ in chronic metabolic alkalosis in the rat. J. Clin. Invest. 72:1385-1395.

20. Maddox, D. A., L. J. Atherton, W. M. Deen, and F. J. Gennari. 1984. Proximal $\mathrm{HCO}_{3}^{-}$reabsorption and the determinants of tubular and capillary $\mathrm{PCO}_{2}$ in the rat. Am. J. Physiol. 247 (Renal Fluid Electrolyte Physiol. 16):F73-F81.

21. Crocker, C. L. 1967. Rapid determination of urea nitrogen in serum or plasma without deproteinization. Am. J. Med. Technol. 33: 361-365.

22. Vurek, G. G., D. G. Warnock, and R. Corsey. 1975. Measurement of picomole amounts of carbon dioxide by calorimetry. Anal. Chem. 47: 765-767. 
23. Alpern, R. J., M. G. Cogan, and F. C. Rector, Jr. 1983. Flow dependence of proximal tubular bicarbonate reabsorption. Am. J. Physiol. 245 (Renal Fluid Electrolyte Physiol. 14):F478-F484.

24. Alpern, R. J., M. G. Cogan, and F. C. Rector, Jr. 1982. Effect of luminal bicarbonate concentration on proximal acidification in the rat. Am. J. Physiol. 243 (Renal Fluid Electrolyte Physiol. 12):F53-F59.

25. Maddox, D. A., and F. J. Gennari. 1986. Load dependence of proximal tubular bicarbonate reabsorption in chronic metabolic alkalosis in the rat. J. Clin. Invest. 77:709-716.

26. Cohn, D. E., K. A. Hruska, S. Klahr, and M. R. Hammerman. 1982. Increased $\mathrm{Na}^{+}-\mathrm{H}^{+}$exchange in brush border vesicles from dogs with renal failure. Am. J. Physiol. 243 (Renal Fluid Electrolyte Physiol. 12):F293-F299.
27. Nord, E. P., A. Hafezi, J. D. Kaunitz, W. Trizna, and L. G. Fine. 1985. $\mathrm{pH}$ gradient dependent increased $\mathrm{Na}^{+}-\mathrm{H}^{+}$antiport capacity of the rabbit remnant kidney. Am. J. Physiol. 249 (Renal Fluid Electrolyte Physiol. 18):F90-F98.

28. Harris, R. C., J. L. Seifter, and B. M. Brenner. 1984. Adaptation of $\mathrm{Na}^{+}-\mathrm{H}^{+}$exchange in renal microvillus membrane vesicles. J. Clin. Invest. 74:1979-1987.

29. Schwartz, G. J., and Q. Al-Awqati. 1985. Carbon dioxide causes exocytosis of vesicles containing $\mathrm{H}^{+}$pumps in isolated perfused proximal and collecting tubules. J. Clin. Invest. 75:1638-1644.

30. Rector, F. C., Jr. 1983. Sodium, bicarbonate and chloride reabsorption by the proximal tubule. Am. J. Physiol. 244 (Renal Fluid Electrolyte Physiol. 13): F461-F471. 